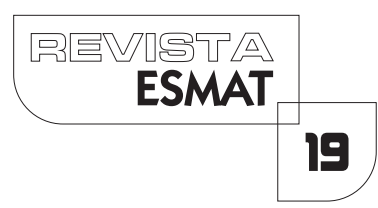

\title{
A RELAÇÃO ENTRE CIDADANIA, DIREITOS HUMANOS E DESENVOLVIMENTO REGIONAL
}

\author{
THE RELATION BETWEEN CITIZENSHIP, HUMAN RIGHTS AND REGIONAL
}

DEVELOPMENT

José Ribamar Mendes Júnior

Juiz de Direito de $3^{a}$ Entrância. Presidente dos Conselhos da Justiça Militar, Órgão do $1^{\circ} \mathrm{Grau}$ de Jurisdição da Justiça Militar do Estado do Tocantins. Segundo Diretor Adjunto da Escola Superior da Magistratura Tocantinense (ESMAT). Diretor de Cursos. Mestre em Prestação Jurisdicional e Direitos Humanos, pela Universidade Federal do Tocantins (UFT). Mestre em Direito Constitucional, pela Universidade de Lisboa (FDUL).E-mail:vrmendes@uol.com.br.

Tarsis Barreto Oliveira

Doutor e Mestre em Direito, pela UFBA. Professor Adjunto de Direito da UFT e da UNITINS. Professor do Mestrado em Prestação Jurisdicional e Direitos Humanos da UFT/ESMAT. Membro do Comitê Internacional de Penalistas Francófonos e da Associação Internacional de Direito Penal. E-mail:tarsisbarreto@uft.edu.br.

\section{RESUMO}

O A discussão no meio acadêmico e científico a respeito da relação entre os direitos humanos, a cidadania, o exercício da cidadania e o desenvolvimento regional é de suma importância. Convém estudar de que forma o entendimento das referidas concepções atuam como elementos propulsores desse avanço local, uma vez que um ambiente participativo e democrático funciona de modo substancial para o progresso; além disso, é relevante a busca pelo desenvolvimento de sujeitos ativos, portadores de visão crítica, que possam atuar como multiplicadores de conhecimento e como protagonistas de suas próprias histórias, bem como sejam capazes de remodelar a realidade local, sendo agentes transformadores do ambiente discriminatório e desigual, combatentes das violações aos direitos. A fim de que sobrevenha o desenvolvimento permanente da região, bem assim daqueles que a integram, é pertinente que haja a identificação das características próprias da localidade e ao mesmo tempo o reconhecimento de suas qualidades e potencialidades, além de uma exploração dos meios acessíveis, estimulação da atuação e cooperação dos atores que compõem o território. É nesse sentido que uma das estratégias para se conceber o desenvolvimento regional é apreendendo os conceitos de direitos humanos, de cidadania e seu exercício, e, do 
mesmo modo, verificar de que forma ocorre o desencadeamento dessas perspectivas no próprio avanço local.

PALAVRAS-CHAVE:Desenvolvimento Regional. Direitos Humanos. Cidadania. Democracia.

\begin{abstract}
The discussion in the academic and scientific community about the relation between human rights, citizenship, the use of citizenship and regional development is very important. Studying how the understanding of these concepts act as driving forces behind this place advance, as a participatory and democratic environment works substantially to progress further, it is necessary to search for the development of active subjects, critical vision carriers which can act as multipliers of knowledge and also as protagonists of their own stories and be able to reshape the local reality, with transforming agents of the discriminatory and unequal environment, fighters of violations of rights. In order to come upon the ongoing development of the region, as well as those that integrate, it is pertinent that there is the identification of the characteristics of the locality and at the same time recognizing its qualities and potential, as well as an exploration of accessible, stimulation the performance and cooperation of the actors in the territory. It is in this sense that one of the strategies to develop regional development is grasping the concepts of human rights, citizenship and exercise, and likewise, verify how is the triggering of these perspectives on the spot advance.
\end{abstract}

KEYWORDS: Regional Development. Human Rights. Citizenship. Democracy.

\title{
I INTRODUÇÃO
}

Oartigo tem como objeto o estudo da relação entre o desenvolvimento regional, os Direitos Humanos, a cidadania e seu exercício, ou seja, busca-se trabalhar a forma como a compreensão desses conceitos - enquanto fatores endógenos do desenvolvimento promovem o avanço local.

A discussão do presente tema justifica-se pela importância de evidenciar a dispensabilidade da vinda de fatores externos como elementos essenciais para que ocorra o desenvolvimento local, isto é, os indivíduos integrantes da região podem (e devem) ser os protagonistas da própria transformação social e econômica. Esse empoderamento, advindo de estímulos do Estado, por meio de políticas públicas e da educação, desenvolve naqueles atores locais a compreensão de cidadania ativa, retirando-os da posição passiva de meros espectadores. 
Para haver progresso permanente numa comunidade, é necessário que haja participação consciente dos atores que formam essa região; para tal, a educação, as ciências sociais e o direito podem trabalhar, de forma interdisciplinar, buscando impulsionar o desenvolvimento regional por intermédio da percepção dos direitos humanos, do exercício da cidadania e da democracia, os quais são, igualmente, elementos propulsores do desenvolvimento pessoal e garantidores da liberdade.

Sabe-se que a educação atua como alicerce da composição e evolução do ser humano e de igual modo na salvaguarda e no fomento de outros direitos sociais, políticos e econômicos, além de ser recurso básico para uma transformação da sociedade.

Pela educação adquirem-se condições mais sensatas para exercer a cidadania, sendo ponto de partida para mutação de conjunturas e ideais sociais discriminatórios e legitimadores de violações. É por meio dela que se superam as desigualdades sociais, desenvolve-se o respeito às diferenças, aos direitos do próximo, bem como se toma conhecimento de seus deveres como participante de uma sociedade.

Se não houver educação adequada desde a base em relação ao convívio social, trazendo a compreensão do exercício da cidadania, dos direitos humanos, do respeito à diversidade, continuará a perpetuação da desigualdade e das demais violações aos direitos.

A efetividade dos direitos humanos e da prática da cidadania conduz ao fortalecimento da democracia, a qual dispõe de princípios basilares: a igualdade e a liberdade, ambos capazes de serem produzidos por meio das atividades educativas.

A educação é fundamental na conscientização dos papéis sociais dos cidadãos e cidadãs. Demonstrar-se-á que abordar essas questões ainda na educação básica traz-se a construção de um saber de poder propagador, criador de nova perspectiva e, consequentemente, de desenvolvimento da região.

Apesar de a chave da estruturação de uma sociedade democrática ser a educação, é imprescindível, dentro da temática Cidadania e Direitos Humanos, que tanto os professores, como os alunos, sejam instigados a entender essas perspectivas diante da sua realidade local, porque remodelar essa realidade só é possível após a compreensão desses conceitos. $\bigcirc$ fato é que o desenvolvimento da localidade exige que essa educação desencadeie cidadãos críticos, ativos e multiplicadores de conhecimento.

O objetivo é compreender os direitos humanos, a cidadania e seu exercício, por meio da educação, como elementos propulsores do desenvolvimento regional. Para tanto, utilizaram-se os métodos dedutivo e dialético, por meio de pesquisa bibliográfica, fazendo uma abordagem qualitativa, com emprego de técnicas indiretas de levantamento literário, doutrinas, legislação, dados estatísticos, planos educacionais, artigos e outros trabalhos acadêmicos. 


\section{UMANOÇÃOSOBRE DESENVOLVIMENTO REGIONAL}

Ao longo dos últimos anos, tem-se percebido certa premência na reformulação das habituais técnicas empregadas na construção de políticas para promover o desenvolvimento nacional, isso porque a sociedade é dinâmica, está em constante mutação, e suas relações e instituições vão se alterando, consequentemente reclamam por novas estratégias que se ajustem a essa recente realidade e a seus anseios. Todavia, não é apenas o teor dessas técnicas (que pode não corresponder às singularidades do local) que sofre problemas, também a sua finalidade e o seu procedimento.

Diz-se a finalidade diante da precisão em trabalhar (ter como objeto e escopo) uma região específica', uma vez que suas problemáticas e peculiaridades comportam-se de forma similares, podendo ser construídas iniciativas mais eficazes. $\bigcirc$ alicerce do desenvolvimento regional precisa ser as características, as aspirações e as habilidades presentes no interior de cada região. Para tanto, é fundamental identificar suas individualidades, fazer uso dos artifícios acessíveis, dando visibilidade à existência de seu próprio potencial, e reconhecer a importância dos atores integrantes daquela localidade, promovendo suas participações e atendendo a seus anseios.

É nesse sentido a explicação quanto ao procedimento, já que muitas vezes a construção dessas políticas regionais tem um direcionamento externo-interno ou de cima para baixo. Não é necessário esperar pela chegada de um desenvolvimento (de uma grande empresa ou um projeto do governo, por exemplo), já que os próprios atores locais podem atuar na transformação política, social e econômica do seu território, por meio dos recursos disponíveis, abandonando a passividade, distanciandose do comportamento de mero expectador, e, mediante a compreensão de cidadania ativa, promover o avanço da sua região.

Esclarece Boiser (1996a, p. 133) a respeito de seis elementos que fazem parte de qualquer território organizado, quais sejam: os atores, as instituições, a cultura, os procedimentos, os recursos e o entorno. $\bigcirc$ desenvolvimento regional "depende da existência, da articulação e das condições de manejo" desses elementos, e explica que este só ocorrerá se a interação for "densa e inteligentemente articulada, mediante um projeto coletivo ou um projeto político regional". Por fim, conclui:

Evidentemente, o desenvolvimento de um território organizado (região, província ou localidade) não depende apenas da existência dos seis elementos descritos, nem da sua

\footnotetext{
'Nesse sentido, trata-se de oposição a iniciativas que façam a sua abordagem tendo como objeto e finalidade grandes regiões (exemplo: âmbito nacional, região norte, região nordeste etc.). "Devem ser substituídas por iniciativas de abrangência subregional ou local, que possam ser melhor calibradas com base em diagnósticos mais precisos da situação e das potencialidades dessas áreas menores, cuja problemática tende a ser mais homogênea" (BANDEIRA, 1999, p.8).
} 
qualidade, mas depende, basicamente, do modo de articulação. Uma articulação densa e inteligente produzirá, inevitavelmente, o desenvolvimento; uma articulação difusa e aleatória impede o surgimento do desenvolvimento. Em qualquer região ou qualquer território organizado devem ser avaliados dois aspectos: como está estruturado cada um dos elementos e como eles se articulam entre si? Para um território, a tarefa básica do desenvolvimento é a de modernizar seus componentes e gerar um projeto coletivo que os articule e direcione. (BOISER, 1996a, p. I4I)

O desenvolvimento regional desencadeia-se no núcleo de uma localidade, é corolário de uma consciência ativa de pertencimento àquela região, a fim de proporcionar artifícios que supram os anseios coletivos. Tal consciência de territorialidade pode ser formada por meio das percepções de cidadania e de direitos fundamentais, capazes de construir agentes participantes ativamente. Assim, entende-se por desenvolvimento regional um processo localizado de mudança social sustentável, que tem como objetivo o progresso permanente da região, da sua comunidade, bem como de cada integrante daquele espaço (BOISER, I 996b). O autor continua:

El desarrollo de una región, que presuponenecesariamentela existência de unproceso de crecimiento económico, se caracteriza, además, por elseguiente conjunto de atributos simultáneos: i) Uncrecienteproceso de autonomía regional de decisión, que significa capacidades regionales cada vez mayores para definir supropio estilo de desarrollo y para usar instrumentos de política congruentes con tal decisión [...] iii) Uncrecientemovimiento de inclusión social, concepto que denota simultáneamente, una mejoría sistemática em lareparticióndelingreso regional entre las personas y una permanente posibilidad de participación de laproblácionenlasdecisiones de competencia de laregión ${ }^{2}$. (BOISER, 1996b, p.35).

\footnotetext{
2 "O desenvolvimento de uma região, o que pressupõe necessariamente a existência de um processo de crescimento econômico, é ainda caracterizada pelo conjunto de atributos simultâneos seguintes: i) um crescente processo de autonomia regional da decisão, que significa capacidades regionais cada vez maiores para definir o seu próprio estilo de desenvolvimento e para usar instrumentos de política consistentes com a tal decisão [...] iii) um crescente movimento do conceito de inclusão social que denota ao mesmo tempo, uma melhoria sistemática na distribuição de renda regional entre as pessoas e uma permanente possibilidade de participação da população nas decisões da região". Tradução realizada pelo presente autor.
} 
Nessa esteira, é possível inferir que o desenvolvimento regional possui natureza interdisciplinar. Ademais, transcende a esfera econômica, englobando as perspectivas sociais, ecológicas, políticas, culturais e pessoais, devendo seus integrantes atuar como protagonistas desse avanço local. Portanto, para iniciar esse progresso demanda-se uma associação de diversas áreas do conhecimento, tendo em vista a multiplicidade de elementos necessários para interagir.

Diante desse novo paradigma da concepção de desenvolvimento é imprescindível buscar compreender os conceitos de direitos humanos, de democracia, de cidadania e de seu exercício, bem como refletir a respeito da educação como fator de evolução e agente de mudança. Entretanto, antes disso, é preciso entender o desenvolvimento como direito assegurado pelo Estado.

\section{O DESENVOLVIMENTO REGIONAL COMO DIREITO HUMANO}

A Declaração sobre o Direito ao Desenvolvimento, de 1986, proclamada pela Assembleia Geral das Nações Unidas, reconheceu o direito ao desenvolvimento como um direito humano. Tendo em vista essa condição, garantiu a toda pessoa ser habilitada a participar do desenvolvimento regional, tanto como sujeito ativo, quanto beneficiário do progresso. Além disso, admite outros pontos essenciais, atribuindo a essa participação não só a característica de ativa, mas também de livre e significativa, bem como a ideia de que é preciso efetivar e salvaguardar os direitos civis, políticos, sociais, econômicos e culturais, e promover e respeitar os direitos humanos e as liberdades fundamentais, para impulsionar o desenvolvimento ${ }^{3}$.

Nestes termos, claramente essa Declaração estabeleceu o ser humano como sujeito central do avanço local. Consolidou que só é factível o desenvolvimento se os

\footnotetext{
${ }^{3}$ De acordo com o disponibilizado no sítio eletrônico da Universidade de São Paulo (USP): "Reconhecendo que o desenvolvimento é um processo econômico, social, cultural e político abrangente, que visa ao constante incremento do bem-estar de toda a população e de todos os indivíduos com base em sua participação ativa, livre e significativa no desenvolvimento e na distribuição justa dos benefícios daí resultantes; [...] Preocupada com a existência de sérios obstáculos ao desenvolvimento, assim como à completa realização dos seres humanos e dos povos, constituídos, inter alia, pela negação dos direitos civis, políticos, econômicos, sociais e culturais, e considerando que todos os direitos humanos e as liberdades fundamentais são indivisíveis e interdependentes, e que, para promover o desenvolvimento, devem ser dadas atenção igual e consideração urgente à implementação, promoção e proteção dos direitos civis, políticos, econômicos, sociais e culturais, e que, por conseguinte, a promoção, o respeito e o gozo de certos direitos humanos e liberdades fundamentais não podem justificar a negação de outros direitos humanos e liberdades fundamentais;" (UNIVERSIDADE DE SÃO PAULO, online).
} 
direitos humanos estiverem efetivados plenamente e se, de igual forma, o exercício dos demais direitos forem assegurados ${ }^{4}$.

Sachs (1998, p. I 50) fala da era do desenvolvimento, fazendo uma analogia à era dos direitos, e leciona:

Assim como os direitos humanos, a noção de desenvolvimento é central nas preocupações da ONU. Ao longo dos últimos 50 anos, ela se enriqueceu consideravelmente. A idéia simplista de que o crescimento econômico por si só bastaria para assegurar o desenvolvimento foi rapidamente abandonada em proveito de uma caracterização mais complexa do conceito, expressa pelas adições sucessivas de epítetos: econômico, social, cultural, naturalmente político, depois viável [sustainable], enfim, último e recente acréscimo, humano, significando ter como objetivo o desenvolvimento dos homens e das mulheres em lugar da multiplicação das coisas.

A noção de desenvolvimento apenas pelo aspecto econômico é restrita ${ }^{5}$, mas não deve ser ignorada, deve ser entendida como meio para atingir outros objetivos (até mesmo o próprio desenvolvimento regional) e como instrumento "de expandir as liberdades desfrutadas pelos membros da sociedade" (SEN, 20 I0, p. I6), não sendo o único elemento motivador das liberdades, já que elas "dependem também de outros determinantes, como as disposições sociais e econômicas (por exemplo, os serviços de educação e saúde) e os direitos civis (por exemplo, a liberdade de participar de discussões e averiguações públicas)" (SEN, 20 I0, p. I6). O aspecto econômico trata-se de uma abordagem quantitativa do progresso, enquanto a interação dos outros aspectos desse paradigma de desenvolvimento compreende um tratamento qualitativo, que vem resultar em qualidade de vida e promoção de outros direitos, portanto, no desenvolvimento humano, social e, por conseguinte, o próprio desenvolvimento econômico.

\footnotetext{
${ }^{4}$ Ranieri (1994, p. 1055) conclui que o direito ao desenvolvimento é um resumo dos direitos fundamentais: "E isto porque sendo uma síntese dos direitos e garantias fundamentais, sua concretização se faz pelo exercício desses mesmos direitos e garantias assegurados pela Constituição Federal, e sua proteção, por extensão, pelos respectivos mecanismos de tutela". ${ }^{5}$ A respeito, explana Aguiar (20 I 5, p. 380): "A ideia de desenvolvimento em sua formulação inicial esteve atrelada à capacidade de produção de bens e serviços (riqueza) que um país pudesse gerar, especialmente por meio de processos de industrialização que revelavam seu progresso a partir da evolução de indicadores econômicos, em especial o Produto Interno Bruto (PIB). Nestes termos, esta visão reduzida de desenvolvimento implicou a ideia de que estivesse relacionado apenas ao conceito de crescimento econômico, no qual, capital, trabalho e renda seriam os únicos componentes da análise".
} 
Smith ( 1996 ) discorre em sua obra denominada "A riqueza das nações" a respeito da relação entre educação e desenvolvimento econômico, ao explanar sobre a produtividade e entender a acumulação de conhecimento de um trabalhador como um instrumento para galgá-la, portanto, apta a lucrar, apreendendo a atuação desse conhecimento na qualidade de capital, no caso, humano ${ }^{6}$. A educação é encarada como o meio indispensável para que haja desenvolvimento, o autor estabelece uma analogia entre uma máquina onerosa e o investimento em aprendizagem ${ }^{7}$, concluindo por ser proveitoso e lucrativo, não apenas para o indivíduo, mas para toda sociedade onde ele vive:

Em quarto lugar, as habilidades úteis adquiridas por todos os habitantes ou membros da sociedade. A aquisição dessas habilidades para a manutenção de quem as adquiriu durante o período de sua formação, estudo ou aprendizagem, sempre custa uma despesa real, que constitui um capital fixo e como que encarnado na sua pessoa. Assim como essas habilidades fazem parte da fortuna da pessoa, da mesma forma fazem parte da sociedade à qual ela pertence. A destreza de um trabalhador pode ser enquadrada na mesma categoria que uma máquina ou instrumento de trabalho que facilita e abrevia o trabalho e que, embora custe certa despesa, compensa essa despesa com lucro. (SMITH, 1996, p. 290).

O Programa das Nações Unidas para o Desenvolvimento (PNUD) elenca como um dos seus objetivos de desenvolvimento sustentável a educação de qualidade, que visa "assegurar a educação inclusiva e equitativa e de qualidade, e promover oportunidades

\footnotetext{
${ }^{6}$ Não são apenas os insumos mecânicos, ou o capital material, que integram o desenvolvimento, mas também o capital humano, desenvolvido por meio da educação, saúde e qualidade de vida. Assim, tanto um quanto o outro, precisam interar para promover o desenvolvimento da região. Não há como negar que o conhecimento tem sido encarado como instrumento essencial para evolução pessoal, social, política, cultural e econômica.

7"Quando se instala uma máquina cara, deve-se esperar que o trabalho extraordinário a ser executado por ela antes que se desgaste permita recuperar o capital nela investido, no mínimo com o lucro normal. Uma pessoa formada ou treinada a custo de muito trabalho e tempo para qualquer ocupação que exija destreza e habilidade extraordinárias pode ser comparada a uma dessas máquinas dispendiosas. Espera-se que o trabalho que essa pessoa aprende a executar, além de garantir-Ihe o salário normal de um trabalho comum, Ihe permita recuperar toda a despesa de sua formação, no mínimo com os lucros normais de um capital do mesmo valor. E isso deve acontecer dentro de um prazo razoável, levando-se em conta a duração muito incerta da vida humana, da mesma forma como se leva em conta a durabilidade mais certa da máquina". (SMITH, 1996, p. I49).
} 
de aprendizagem ao longo da vida para todos" (PROGRAMA DAS NAÇÕES UNIDAS PARA O DESENVOLVIMENTO, online), que tem como meta:

\begin{abstract}
4.7 Até 2030, garantir que todos os alunos adquiram conhecimentos e habilidades necessárias para promover o desenvolvimento sustentável, inclusive, entre outros, por meio da educação para o desenvolvimento sustentável e estilos de vida sustentáveis, direitos humanos, igualdade de gênero, promoção de uma cultura de paz e não violência, cidadania global e valorização da diversidade cultural e da contribuição da cultura para o desenvolvimento sustentável.
\end{abstract}

Sendo assim, não se pode negar que o desenvolvimento regional, necessariamente, só ocorre depois da garantia do desenvolvimento do homem, ou seja, dos sujeitos integrantes daquele local, e, do mesmo modo, da proteção dos seus direitos fundamentais, que só serão alcançados por intermédio da participação ativa e consciente dos atores locais, que pode ser estimulada pela educação e compressão dos conceitos de cidadania e dos próprios direitos humanos. "Desenvolver e fortalecer um sistema democrático é um componente essencial do processo de desenvolvimento" (SEN, 2010, p. 207).

\title{
4 ADEMOCRACIAE CIDADANIA COMO ELEMENTOS DO AVANÇO LOCAL
}

preâmbulo da Constituição da República Federativa Brasileira consagrou e descreveu a instituição do Estado Democrático de Direito como:

[...] destinado a assegurar o exercício dos direitos sociais e individuais, a liberdade, a segurança, o bem-estar, o desenvolvimento, a igualdade e a justiça como valores supremos de uma sociedade fraterna, pluralista e sem preconceitos, fundada na harmonia social e comprometida, na ordem interna e internacional, com a solução pacífica das controvérsias [...]. (BRASIL, online).

Nota-se que o Estado não é apenas de Direito, regado por normas, mas é também Democrático, reconhecendo a dignidade da pessoa humana como seu fundamento, salientando-se dois sustentáculos, quais sejam: a liberdade e a igualdade. A noção de liberdade relacionada além da ideia de ação e decisão, mas também associada à existência de oportunidades autênticas que a pessoa tem, considerando suas condições pessoais e sociais, para exercer essa liberdade.

Quanto à igualdade, só é possível ser participante do Estado Democrático se seus sujeitos possuírem iguais oportunidades, até mesmo de compreender e de fazer 
escolhas, se não for assim, a liberdade será meramente formal e não efetiva ${ }^{8}$. Com a existência das desigualdades, conclui-se que "democracia e direitos não são um fim em si mesmo, mas os meios pelos quais se pode fazer (de forma humanamente humana) o caminho de uma existência feliz" (LOPES; MELO, 2008, p. 10), ou seja, a garantia daqueles asseguram a dignidade humana e viabilizam uma qualidade de vida.

A Constituição da República Federativa do Brasil garante que todo poder do Estado emana do povo, assegurando, portanto, o princípio da soberania popular, de igual forma o direito subjetivo à participação, que deve ser proporcionado com igualdade de chances na formação democrática da vontade (HABERMANS, 2012, p. 212). A única forma de ver exercida a soberania popular é por meio da atribuição dos direitos humanos aos atores sociais.

Dessarte, a construção do Estado Democrático de Direito, bem como seu desenvolvimento necessitam de uma cidadania e participação democrática dos sujeitos integrantes, detentores de capacidade de discernimento. Habermas (20 I 2), ao tratar da teoria do discurso, leciona que o princípio da soberania do povo sugere que do poder comunicativo dos cidadãos infere-se todo o poder político e enfatiza serem os sujeitos integrantes os únicos aptos a produzir o poder comunicativo de convicções comuns, a partir do seu meio e dos recursos disponíveis:

O exercício do poder político orienta-se e se legitima pelas leis que os cidadãos criam para si mesmo numa formação da opinião e da vontade estruturada discursivamente. Quando se considera essa pratica como um processo destinado à resolver problemas, descobre-se que ela deve a sua forma legitimadora a um processo democrático destinado a garantir um tratamento racional de questões política. A aceitabilidade racional dos resultados obtidos em conformidade com o processo explicase pela institucionalização de formas de comunicação interligadas que garantem de modo ideal que todas as questões relevantes, temas e contribuições sejam tematizados e elaborados em discursos e negociações, na base das melhores informações e argumentos possíveis. Esta institucionalização jurídica de determinados processos e condições da

8 "O Estado democrático se justifica como meio para que essas liberdades sejam guarnecidas e estimuladas - inclusive por meio de medidas que assegurem maior igualdade entre todos, prevenindo que as liberdades se tornem meramente formais. $\bigcirc$ Estado democrático se justifica, também, como instância de solução de conflitos entre pretensões colidentes resultantes dessas liberdades. A efetividade dessas liberdades, de seu turno, presta serviço ao regime democrático, na medida em que viabiliza a participação mais intensa de todos os interessados nas decisões políticas fundamentais" (MENDES; BRANCO, 20 I3, p. 263). 
comunicação torna possível um emprego efetivo de liberdades comunicativas, iguais e simultaneamente estimuladas para o uso pragmático, ética e moral da razão pratica, ou seja, para a compensação equitativa de interesses. Além disso, o princípio da soberania do povo pode ser considerado diretamente sob o aspecto do poder. A partir desse ângulo ele exige a transmissão da competência legislativa para a totalidade dos cidadãos que são os únicos capazes de gerar, a partir do seu meio, o poder comunicativo de convicções comuns. Ora, a decisão fundamentada e obrigatória sobre políticas e leis exige, de um lado, consultas e tomadas de decisão face to face. De outro lado, nem todos os cidadãos podem 'unir-se' no nível de interações simples e diretas, para uma tal prática exercitada em comum. (HABERMANS, 20 I2, p. 2I3).

A democracia resulta tanto do direito como do dever de participar. Na democracia contemporânea, um dos seus grandes entraves diz respeito à qualidade dessa participação, já que é preciso que todos os integrantes da sociedade detenham iguais possibilidades de participar e também de adquirir conhecimento suficiente que os tornem capazes de compreender as questões locais e influenciar nas decisões, tornando-se sujeitos ativos inteligentes (CANÇADO; PEREIRA; TENÓRIO, 20I 5, 910).

Garantidas a liberdade e a igualdade a esses atores sociais, eles poderão exercer uma participação democrática, e para que essa participação seja realizada com qualidade é necessária a promoção e a compreensão dos conceitos de direitos humanos, de cidadania e de seu exercício, ações estas que decorrem de práticas educacionais as quais proporcionem o empoderamento pessoal e o da comunidade, porque uma educação nestes termos estimula o potencial dos integrantes; ativa suas capacidades; fomenta a visão crítica e a participação ativa e inteligente, desencadeando o processo de desenvolvimento local. Assim, a educação como prática de liberdade é substancial para o processo de desenvolvimento regional, já que decisiva para o exercício da cidadania, diante da capacidade de conscientização política, civil e territorial.

\section{O PAPEL DA EDUCAÇÃO NO ESTADO DEMOCRÁTICO DE DIREITO COMO PROPULSORLOCAL}

No interior de um Estado Democrático de Direito, a escola é instrumento de mudança social e condição de desenvolvimento. Uma prática educacional que abrange a proteção e reconhecimento dos direitos humanos e a apreensão da cidadania e seu exercício viabiliza gerar nos sujeitos visão crítica, capacidade de atuarem como indivíduos ativos na luta e na realização de seus direitos e deveres, bem como na promoção do desenvolvimento pessoal, econômico e social. "Por isso, uma educação 
voltada para a disseminação de uma cultura de direitos humanos tem de ser capaz, acima de tudo, de propugnar a construção de uma sociedade preparada para o exercício da autonomia, condição fundamental para o exercício da cidadania" (BITTAR, 20 I I , p. 42).

É possível, ao reconhecer ao indivíduo o status de autônomo", despertar uma transmutação das concepções sociais discriminatórias, que legitimam as transgressões aos direitos fundamentais, que fomentam as injustiças, as violências e as desigualdades. Da mesma forma, proporcionar e estimular, por meio dessa educação, a participação ativa como cidadãos conscientes, a tolerância, o respeito ao próximo, a solidariedade, a igualdade, a liberdade, os valores consoantes aos princípios da democracia, favorecendo o desenvolvimento sustentável, humano e da justiça social.

A Constituição Federal, ao discorrer a respeito da educação no artigo 205, dispôs o pleno desenvolvimento da pessoa e seu preparo para o exercício da cidadania como seus escopos ${ }^{10}$. Ou seja, a educação é alicerce do Estado Democrático de Direito e tem papel fundamental na conscientização dos papéis sociais dos cidadãos e das cidadãs. Não sendo satisfatória a preparação unicamente para vida profissional por meio da educação técnica (RANGEL, 2008, p. 95), deixando claro o constituinte que a educação tem uma missão ainda mais importante, um desenvolvimento pessoal capaz de gerar exercício da cidadania pleno, sujeitos ativamente participativos que, por sua vez, modifiquem o seu meio e fomentem o desenvolvimento local.

A construção de atores que venham a ser protagonistas do progresso da sua localidade deve começar ainda na educação básica, independentemente de na atual condição de criança (não aptas a exercerem seus direitos políticos de forma plena) essas são pessoas com dignidade, não podendo haver inércia quanto aos seus direitos fundamentais, seu direito à educação, porque por meio deste é possível ter evolução pessoal que as capacite para o exercício da cidadania, resultando sujeitos críticos, com participação ativa no processo democrático, multiplicadores do conhecimento e promotores de outros direitos aptos a gerir o desenvolvimento.

\footnotetext{
9 "Autonomia é, fundamentalmente, em seu traçado interior, liberdade. Significa posse de um estado de independência com relação a tudo o que define a personalidade heteronomamente. Isso importa na capacidade de analisar e distinguir, para o que é necessária a crítica, pois somente ela divisa o errado no aparente certo, o injusto no aparente justo". (BITTAR, 20 I I, p. 47).

10"Trata-se da realização do ensino e da aprendizagem objetivando a compreensão teórica e prática (saber e saber fazer), pelo cidadão, da amplitude e dos limites de seus direitos e deveres fundamentais, dos mecanismos e procedimentos para o exercício desses, assim como para a necessária fiscalização do cumprimento adequado dos deveres públicos do Estado. Tal conjunto de objetivos culmina na formação de um cidadão integrado em uma democracia efetivamente participativa, na qual o Estado e ávida pública são, permanentemente, aprimorados e fiscalizados por cada um do povo em prol do bem comum" (RANGEL, 2008, p. 75).
} 
Nesse sentido, fica clara a necessidade da criação de uma educação com capacidade de formar sujeitos detentores de autonomia. Rangel esclarece que "a melhor educação deve buscar, sempre, a meta da ação evolutiva, a transformação da pessoa para melhor, assim como do estado e da sociedade em que se realiza" (2008, p. I 19), ou seja, propicia a essas crianças os recursos que podem ser utilizados para intervir na própria realidade.

O Plano Estadual de Educação do Tocantins (PEE/TO), 20 I 5-2025, traça algumas diretrizes inseridas nessa abordagem, quais sejam: superação das desigualdades educacionais, com ênfase na promoção da cidadania e na erradicação de todas as formas de discriminação; promoção da melhoria da educação com qualidade na formação integral e humanizada; formação para o trabalho e para a cidadania, com ênfase nos valores morais e éticos em que se fundamenta a sociedade; promoção humanística, científica, cultural e tecnológica do Estado; promoção dos princípios do respeito aos direitos humanos, à diversidade e à sustentabilidade socioambiental. Além disso, possui como uma de suas estratégias garantir a oferta com qualidade social do ensino fundamental, por meio da

reformulação dos processos de ensino e aprendizagem, que considere a formação ética, a autonomia intelectual e o pensamento crítico que forme sujeitos de direitos e de deveres, ressignificando o cotidiano escolar, capaz de promover uma base unitária, de pensamento e compreensão das determinações da vida social e produtiva, fortalecendo o protagonismo investigativo, que articule o trabalho e a cultura na perspectiva da emancipação humana. (TOCANTINS, 20 I 5, online).

Assim, o desígnio por revisar o processo de ensino busca a evolução pessoal dos indivíduos e uma formação cidadã que resulte um senso crítico e uma participação ativamente inteligente com capacidade de remodelar não apenas seu quotidiano escolar, mas também de desenvolver uma compreensão da vida social, favorecendo uma emancipação humana e, por conseguinte, um progresso local. É nesse sentido em que se consta a educação como alicerce da estruturação de uma sociedade democrática, sendo fundamental propiciar aos alunos e aos professores a compreensão da sua realidade local, por meio da apreensão das perspectivas de cidadania e de direitos humanos, para então atuarem como protagonistas do desenvolvimento.

O fato é que sem educação com qualidade, que promova a democracia e os direitos fundamentais, não é possível conceber uma dinâmica de desenvolvimento regional. Assim, é fundamental a construção de sujeitos capazes de participar do processo democrático que possuam visão crítica, atuem como multiplicadores de conhecimento e também como protagonistas da mudança da sua realidade local, por meio do melhor exercício da cidadania e da promoção dos direitos humanos, que são essenciais para estimular o desenvolvimento na região. 


\section{CONCLUSÃO}

Nesse seguimento, relacionar as perspectivas dos direitos humanos, da cidadania e do desenvolvimento regional, é vinculá-las à educação, diante da manifesta primordialidade em preparar os sujeitos locais para o envolvimento e participação ativa na dinâmica social, como detentores de potencialidade capazes de modificar sua região, produzindo avanço.

alcance de cidadãos críticos, ativos e multiplicadores desse conhecimento apto a desencadear o desenvolvimento de sua região deve se iniciar com antecedência, ainda em idade tenra, na educação básica. Precisa-se desenvolver uma educação capaz de gerar autonomia nos sujeitos regionais, porque propicia a essas crianças recursos que podem ser utilizados para intervir na própria realidade, podendo atuar como protagonistas do progresso local.

Ainda que as crianças não se encontrem na condição de cidadãos politicamente definidos, tal situação não acarreta indiferença no que se refere a seus direitos fundamentais, a seu direito à educação, a seu direito de aprender sobre cidadania e exercitá-la. Tais direitos proporcionam a cognição necessária para que esses sujeitos possam participar do processo democrático e, portanto, promover outros direitos e fomentar o desenvolvimento.

Assim, a escola, por meio das práticas educacionais, desempenha sua função de modo a constituir gerações informadas, com capacidade crítica, propagando a concepção de direitos humanos, cidadania e exercício da cidadania, considerando-se tais noções como alicerce da democracia, bem como da participação na vida política e pública, que resultará na promoção do desenvolvimento regional, em diversas perspectivas, sejam elas, econômicas, pessoais e sociais.

\section{REFERÊNCIAS}

AGUIAR, Marcus Pinto. Direitos sociais: entre o crescimento econômico e o desenvolvimento humano. In: HOLANDA, Ana Paula Araújo de; CAULA, Bleine Queiroz, org. Direitos humanos: histórico e contemporanealidade. Edição especial. vol. 2. Rio de Janeiro: Lumen Juris, 20 I 5. cap. 18, p. 367-388.

BANDEIRA, Pedro. Participação, articulação de atores sociais e desenvolvimento regional. Texto para discussão n. 630. Brasília, 1999. Disponível em: <http://repositorio.ipea.gov.br/bitstream/l 1058/2758/I/td_0630.pdf>. Acesso em: 25 ago. 2016.

BITTAR, Eduardo C. B. Democracia, justiça e direitos humanos: estudos de teoria crítica e filosofia do direito. São Paulo: Saraiva, 20 I I . 
BOISIER, Sergio. Em busca do esquivo desenvolvimento regional: entre a caixa-preta e o projeto político. Planejamento e políticas públicas, n |3, p. I I2- | 43, jun. 1996.

- Modernidad y territorio. Instituto latinoamericano y del Caribe de planificación económica y social - ILPES. Santiago de Chile: 1996.

BRASIL. Constituição da República Federativa do Brasil de 1988. Disponível em: <http://www.planalto.gov.br/ccivil_03/constituicao/constituicaocompilado.htm>. Acesso em: 25 ago. 2016.

CANÇADO, Airton Cardoso; PEREIRA, José Roberto; TENÓRIO, Fernando Guilherme. Fundamentos teóricos da gestão social. Desenvolvimento Regional em debate-DRd., v. 5, p. 4-19,2015.

CERVO, Amado Luiz; BERVIAN, Pedro Alcino; DA SILVA, Roberto. Metodologia científica. 6. ed. São Paulo: Pearson Prentice Hall, 2007.

LAKATOS, Eva Maria; MARCONI, Marina de Andrade. Fundamentos de metodologia científica. 5. ed. São Paulo: Atlas, 2003.

LOPES, José Rogério; MÉLO, José Luiz Bica de. Democracia, desigualdades e direitos desterritorializados: um esboço da questão. Ciências Sociais Unisinos, v. 44, p. 5- 12 , 2008.

MENDES, Gilmar Ferreira; BRANCO, Paulo Gustavo Gonet. Curso de direito constitucional. 8. ed. rev. e atual. São Paulo: Saraiva, 2013.

PROGRAMA DAS NAÇÕES UNIDAS PARA O DESENVOLVIMENTO. Os objetivos de Desenvolvimento sustentável. Disponível em: <http://www.undp.org/content/brazil/pt/home/post-20 I 5/sdg-overview/goal4.html >. Acesso em: 26 ago. 2016.

RANGEL, Rodrigo Costa Vidal. Educação constitucional, cidadania e estado democrático de direito. Porto Alegre: Núria Fabris, 2008.

RANIERI, Nina Beatriz Stocco. Direito ao desenvolvimento e direito à educação: relações de realizações e tutela. Revista de Direito Constitucional e Internacional. RDCl 06/I24. p. 1055-1070. jan.mar.// 994.

SACHS, Ignacy. O desenvolvimento enquanto apropriação dos direitos humanos. Estudos Avançados, São Paulo, v. 12, n. 33, p. I 49- I 56, aug. 1998. 
SEN, Amartya. Desenvolvimento como liberdade. São Paulo: Companhia das Letras, 2010.

SEVERINO, Antônio Joaquim. Metodologia do trabalho científico. 23. ed. rev. e atual. São Paulo: Cortez, 2007.

SMITH, Adam. A riqueza das nações: investigação sobre sua natureza e suas causas. v. I. São Paulo: Nova Cultural, 1996.

TOCANTINS. ASSEMBLEIA LEGISLATIVA. Lei $n^{\circ} 2.977$, de 08 de julho de 2015. Publicada no Diário Oficial $n^{\circ} 4.41$ I. Disponível em: <http://www.al.to.gov.br/arquivo/38073>. Acesso em: 25 ago. 2016.

TOCANTINS. SECRETARIA DA EDUCAÇÃO, JUVENTUDE E ESPORTES. Série Histórica do número de Unidades Escolares, 1989 a 2015 - Tocantins. Disponível em: <https://docs.google.com/spreadsheets/d/IPJOZ9VIHIp2YOvu62kb IQt2ir9jCbXeOHhwejHEj3yQ/edit\# gid=980 I 257/6> . Acesso em: 26 ago. 20 I 6.

Número de matrículas na educação básica - ensino regular, especial e educação de jovens e adultos (eja), ensino fundamental, anos iniciais e anos finais e ensino médio, segundo a regional e o município, 20I5. Disponível em: $<$ https://docs.google.com/spreadsheets/d/IUpWJtEQejEls8wy9ELhr6hCk7AHQopx p-y755uktrTg/edit\# gid=0\&fvid = $179|6| 577 \mid>$. Acesso em: 26 ago 2016 .

Número de matrículas na educação básica - ensino regular, especial e educação de jovens e adultos (EJA), ensino fundamental, segundo a regional Tocantins 2015. Disponível em: <https://docs.google.com/spreadsheets/d/IU pWJtEQejEls8 wy9ELhr6hCk7AHQopxp-y755uktrTg/edit\# gid= | 64047 | 526 >. Acesso em: 26 ago. 2016.

UNIVERSIDADE DE SÃO PAULO (USP). Declaração sobre o direito ao Desenvolvimento - 1986. Disponível em: <http://www.direitoshumanos .usp.br/index.php/Direito-ao-Desenvolvimento/declaracao-sobre-o-direito-aodesenvolvimento.html> . Acesso em: 26 ago. 2016.

Recebido em: 18/07/2019

Aprovado em: 02/0 I/2020 